\title{
The Application of the PBL Teaching Mode in the Rehabilitation Nursing of Undergraduate Education
}

\author{
Cheng Meng ${ }^{1,2}$, Guo Tianxiao ${ }^{2}$, Zhao Chunshan ${ }^{1 *_{\mathrm{i}}}$ \\ School of Nursing, Beihua University ${ }^{1}$, Jilin Medical College ${ }^{2}$
}

\begin{abstract}
In order to discuss the application effect of the teaching mode based on the problem-based learning (PBL) in the Rehabilitation Nursing of undergraduate education, the 2016 undergraduate nursing students in our institution were divided into PBL group (117 people) and lecture-based learning (LBL) group ( 120 people) in this research, and the students in these two groups were taught Rehabilitation Nursing with PBL and LBL respectively, then, the teaching effects of these two teaching modes were compared. The result showed that the theoretical knowledge test scores, clinical operation test scores and questionnaire scores of the observation group were obviously higher than the control group, indicating that the teaching effect of the PBL group was significantly higher than the LBL group.
\end{abstract}

Keywords-PBL; Rehabilitation Nursing; Undergraduate education

\section{INTRODUCTION}

At the beginning of the 21 st century, with the social development, people's gradual increase of medical knowledge and technology requirements burden many medical students. In the past, the lecture-based learning (LBL) advocated that teachers teach knowledge and students listen passively, the class model is too mechanized, causing the lack of initiative of students, so cultivating the self-learning ability of students became the primary goal of contemporary medical education [1].Therefore, the Problem-Based learning (PBL) came into being, and was widely accepted and applied [2]. PBL was first put forward by an American psychiatric professor, Barrow, in the early year of 1996. Recently, this method has been a popular and high-profile teaching reform mode internationally, and many scholars have indicated through researches that PBL could effectively increase the active thinking, problem analysis and solving ability of the students, also enhance the awareness of communication and cooperation of them [3].

Rehabilitation Nursing is an important, decisive and indispensable content of rehabilitation medicine, which is a strongly comprehensive specialized course formed by the combination of professional knowledge of rehabilitation and nursing, gradually becoming one of the required courses of nursing students. The course attaches much importance to cultivate students to establish a perfect theoretical system and to improve their practice and expressiveness ability [4]. PBL is raised relative to lecture-based learning, advocating that mainly based on students and partially based on teacher comments, students could get to know course-relative knowledge via textbook reference, database retrieval or using other media by themselves, and finally solve the problems in the forms of group comprehensive analysis, discussion and teacher's explanation and comments [5]. As a new educational concept, PBL is on its start-up stage of teaching process implementation in Rehabilitation Nursing. This research aims to apply PBL teaching method to Rehabilitation Nursing undergraduate class teaching, and to discuss its teaching effects. The report results are as follows:

\section{OBJECTS AND METHODS}

\section{A. Research objects and groups}

We chose 237 undergraduate nursing students of 2016 grade in our school, including 117 from three top-up classes and 120 from three undergraduate nursing classes, and we took three top-up classes as observation group (117 students) taught with PBL teaching method, and three undergraduate nursing classes as control group (120 students) taught with LBL teaching method. The students in two groups had no obvious difference in terms of age, basic culture education and professional knowledge level $(\mathrm{P}>0.05)$.

\section{B. Methods}

\section{1) Teaching methods}

The control group used LBL teaching method which emphasizes the class mode "teacher teaching, students listening", teaching through making the PPT according to the syllabus and teaching plan strictly, and students in this group were taught combining with clinical cases during the class [6].

The observation group use PBL teaching method, including asking questions, random grouping, looking up information, analysis and discussion, group report, teacher's comments and finally summary. These six steps replaced the teaching mode done by one person. Main processes are as follows: (1) introducing cases and asking questions: before teaching theoretical knowledge of a disease, the teacher made PBL implementation manual related to the course one week ahead, and put forward questions related to the course, taking the rehabilitation nursing of coronary heart disease patients as an example, the teacher could introduce clinical cases, and then raised questions as follows according to the information provided by cases: (1) the cause of coronary heart disease; (2) staging and performance of coronary heart disease; (3) rehabilitation nursing assessment of coronary heart disease; (4) rehabilitation nursing measures of coronary heart disease patients; (5)rehabilitation nursing instruction of coronary heart 
disease patients. (2) Random grouping: 8 students in one group randomly, each group designated a team leader, recorder and reporter, the group leader was responsible for distributing PBL implementation manual and task division within the group; the recorder was responsible for summarizing and recording results and doubts; each discussion group elected a student as reporter, who would report the group discussion results and list difficulties in the class after discussion; the team positions were within the regular replacement. One week before teaching, the teacher distributed established PBL implementation manuals to each group. (3) Looking up information: students in groups as a unit, positively obtain knowledge related to the disease aiming at teacher's questions via textbook reference, database retrieval or other media, so that they could obtain materials structurally and purposefully. (4) Analysis and discussion: 15 minutes before teaching, there was a group discussion, students would organize and summarize the related information they had obtained, and list difficulties they met in the process of searching knowledge. In the whole process, the teacher only played the role of organization, instruction and inspiration in the course. (6) Teacher's comments: the teacher finally gave comprehensive comments on discussion results of each group, and gave answers to the listed difficulties. (7) Summary: this method could help students arrange the perfect knowledge they had obtain structurally, and produce a structural knowledge system. In terms of missing or lack of understanding, the teacher would give detailed explanation, so that students could understand the rehabilitation nursing knowledge of the disease comprehensively [7].

\section{2) Textbooks and teachers}

Students in two groups both used Rehabilitation Nursing edited by Yan Tiebin (People's Health Publishing House, 2012) as the textbook, and independently chose reference materials; students in two groups were taught by the same teacher, who had rich teaching experience.

\section{3) Teaching effect evaluation}

(1) Examination: when the course ended, the teacher made test papers, including theoretical knowledge assessment in form of closed book and clinical operation skills assessment, the question form of the theoretical knowledge assessment constituted five types, noun explanation, blank filling question, single choice question, short answer question and case analysis, covering all the knowledge points of the syllabus; the contents of the clinical operation skills assessment constituted rehabilitation nursing common techniques, like endurance training, body shift training, walking training and so on. The students were examined according to operating requirements and processes strictly, two students cooperated, one simulated the patient, the other operated technical operation on him/her, and they were required to express operation points during the process in oral form. The full scores of theoretical and operation skills assessment were both 100, and the teaching effects were compared through the scores of students in two groups.

(2) Questionnaires: when the course ended, we distributed questionnaires to students in two groups respectively, using anonymous survey method, including five contents, "interest and hobbies stimulation", "operational skills improvement", "problem-solving skills improvement", "communication skills improvement", and "cooperation skills improvement", with two alternative answers "agree" and "disagree", in order to assess the teaching effects of students exhaustively and comprehensively. 237 questionnaires were distributed on the spot totally, 117 distributions and 117 recycles in the observation group; 120 distributions and 120 recycles in the control group, the recovery rate was $100 \%$, with zero invalid questionnaire, data verified.

\section{Statistical method}

We used SPSS 19.0 to operate the input and statistical analysis of data, all data were shown as $x^{\overline{ }} \pm \mathrm{s}$, the measurement data were pairwise compared using $\mathrm{t}$ test; $\mathrm{x}^{\wedge} 2$ test was used to pairwise compare the counting data. $\mathrm{P}<0.05$ means the difference showed statistical significance.

\section{RESULTS}

All teaching effect scores of PBL teaching mode were obviously higher than LBL teaching mode (Table 1 Table 2).

TABLE I. THE ASSESSMENT RESULTS OF STUDENTS IN TWO GROUPS $\left(\mathrm{X}^{-} \pm \mathrm{S}\right)$

\begin{tabular}{|c|c|c|c|}
\hline Group & $\mathrm{n}$ & Theoretical assessment & Operation skills assessment \\
\hline Control group & 120 & $81.08 \pm 9.62$ & $75.29 \pm 8.30$ \\
\hline Observation group & 117 & $87.32 \pm 7.23$ & $82.64 \pm 10.48$ \\
\hline
\end{tabular}

TABLE II. THE QUESTIONNAIRE RESULTS OF STUDENTS IN TWO GROUPS [(N) \%]

\begin{tabular}{|c|c|c|c|c|c|}
\hline Group & $\begin{array}{c}\text { Interest and } \\
\text { hobbies } \\
\text { stimulation }\end{array}$ & $\begin{array}{c}\text { Operational } \\
\text { skills } \\
\text { improvemen } \\
\mathrm{t}\end{array}$ & $\begin{array}{c}\text { Problem-solving } \\
\text { skills } \\
\text { improvement }\end{array}$ & $\begin{array}{c}\text { Communication } \\
\text { skills } \\
\text { improvement }\end{array}$ & $\begin{array}{c}\text { Cooperation } \\
\text { skill } \\
\text { improvement }\end{array}$ \\
\hline
\end{tabular}


Table II, cont.

\begin{tabular}{|c|c|c|c|c|c|}
\hline Control group & $62(51.67 \%)$ & $74(61.67 \%)$ & $70(58.33 \%)$ & $58(48.33 \%)$ & $60(50 \%)$ \\
\hline Observation group & $93(79.49 \%)$ & $88(75.21 \%)$ & $92(78.63 \%)$ & $96(82.05 \%)$ & $94(80.34 \%)$ \\
\hline
\end{tabular}

\section{DISCUSSION}

Rehabilitation Nursing is a comprehensive course that takes the disabled, the elderly, patients with chronic diseases as serving objects, with the related theories of rehabilitation nursing to give professional assessment for patients and people in need, and applying related rehabilitation nursing techniques and functional exercise methods to improve or recover the function levels of target groups, and to improve their life quality, in order that they could return to society earlier [8]. The application of PBL mode in the teaching process of Rehabilitation Nursing is helpful for students to improve and produce the interest on learning related knowledge of rehabilitation nursing, to improve motivation, to guide students to use divergent thinking, and to think comprehensively about the problems; on the other hand, it can break the traditional fixed mode "teaching and learning", encourage students to thinking independently, and to communicate with teachers and classmates when necessary, and enhance the group cooperative relationship in the process of obtaining knowledge, also improve communication and exchange. Students could assess, analyze and solve the problems by theory with practice and flexibly using the knowledge they have obtained. PBL teaching mode transfer the focus of teaching to students, which is extremely important in promoting their comprehensive quality.

PBL teaching mode has been used widely, as reported in WHO: there are around 1700 medical colleges all over the world using PBL teaching mode, and this tendency is still increasing continuously [9]. In recent years, many colleges both at home and abroad have introduced PBL mode into medical class, and have furthered deep exploration and try. On the whole, our country started PBL teaching mode later than western countries, our institute has begun the learning mode under PBL since 2010, and we found some shortcomings of PBL mode in the teaching processing, firstly, PBL teaching mode advocates that students should search answers fully exerting subjective initiative to use resources and media, which consumes a lot of time and energy, so it potentially increase the learning load of the students with heavy academic. Secondly, for some olderly teachers, they would feel powerless and lost when suddenly accepting flexible PBL teaching mode because the ingrained education way. From the view of students, it will be an adapted process for them to change education mode, because there has been a long-term acceptance of LBL teaching mode for students. Thirdly, the implement of PBL teaching method need high quality of teachers, which requires teachers to fully understand and master the essence of PBL teaching mode when changing traditional teaching concept, and learn to control the entire teaching process. Fourthly, the purpose of introducing PBL teaching mode is to avoid the "teaching and learning" method in the LBL teaching mode, and to fully mobilize the students' subjective initiative. During the implementation process, it requires students to take the most advantage of various media, like document retrieval in library, database and facilities like textbooks and so on, which needs a lot of financial support from educational institutions, to provide students with highquality and convenient learning conditions.

\section{CONCLUSION}

In summary, PBL teaching mode obtained good teaching effects in the Rehabilitation Nursing of undergraduate education, and was loved by the majority of students. However, we should pay attention to the occurrence of potential problems when implementing a new teaching mode. So, one of the key research directions of current educators is to comprehensively evaluate current resources combined with China's unique teaching characteristics, and finally revise and plan to apply it in the teaching classes.

\section{ACKNOWLEDGEMENT}

The research work was partially supported by the Key Teaching Reform Research Projects of Beihua University under Grant NO.201709.The corresponding author is Zhao Chunshan, Female, (1980-), Doctor's degree.

\section{REFERENCES}

[1] BretzRD,Thopset RE.Comparing traditional and integrative learing methods in organizational training programs[J]. J Appl Psychol, 1992, 77(6): 941-951.

[2] Zhang Xiaoxia. The application of WPBL teaching method in nursing education [J]. Health Vocational Education, 2015, 33(4): 49-50.

[3] Prasad KN,Prasad A,Verma A,et al. Human cysticercosis and Indian scenario: a review [J]. J Brosci, 2008, 33(4): 571-582.

[4] Yan Tiebin. Rehabilitation Nursing[M]. Beijing:People's Health Publishing House, 2012.

[5] Yang Kehu, Tian Jinhui, Ma Bin, et al. The tentative exploration of Evidence-based Medicine course teaching mode in LanZhou University[J]. Chinese University Teaching, 2009, (4): 57-59.

[6] Yan Chunying, Li Hong, Huang Jian, et al. The research: the application of the combination of SSP and PBL in the nursing teaching ward round of Obstetrics and Gynecology[J]. Nursing Research, 2010, (35): 3276.

[7] Yang Yaofang. The analysis of the typical problem-centric teaching process[J]. Foreign Medicine•Medical Education Fascicule, 1994, 5(4): $150-152$.

[8] Shi Fengying. Rehabilitation Nursing [M]. Beijing: People's Health Publishing House, 2008.

[9] Li Xiaodan, Zhang Shaolin. PBL: a new medical teaching mode[J]. The Journal of Branch Campus of the First Military Medical University, 2004, 27(1): 88-90. 